\title{
Changes on the fine sediment dynamics after the Port of Rio Grande expansion
}

\author{
P. D. Silva, P. V. Lisboa, and E. H. Fernandes \\ University of Rio Grande (FURG), Oceanographic Institute (IO-FURG), Caixa Postal 474, CEP 96201-900, \\ Rio Grande, RS, Brazil \\ Correspondence to: P. D. Silva (pdias5@yahoo.com.br), P. V. Lisboa (paulovictor_fjv@hotmail.com), \\ E. H. Fernandes (e.fernandes@furg.com.br)
}

Received: 29 October 2013 - Revised: 7 August 2014 - Accepted: 4 November 2014 - Published: 14 January 2015

\begin{abstract}
The Patos Lagoon estuary is a reservoir of fine sediments derived from the continental basin, which is exported to the coastal area through a narrow channel with average discharge of $2000 \mathrm{~m}^{3} \mathrm{~s}^{-1}$. The Port of Rio Grande is located in this connection channel between the Patos Lagoon and the Atlantic Ocean, and recently received investments from the Brazilian Government to expand its draft and modify the configuration of the breakwaters located at the mouth. The objective of this study is to investigate changes in the fine sediment dynamics in the estuarine and coastal region, after the modernization work carried out at the Port of Rio Grande. The study was conducted using a three-dimensional numerical model (TELEMAC-3D) coupled with a sediment in suspension and morphological model (SediMorph). Results were analyzed in a comparative way in relation to the deposition pattern observed in these regions before and after the construction work. Results indicate that there was a change in the deposition pattern and redistribution of sediment at the bottom due to hydrodynamic changes resulting from the new configuration of the breakwaters and progressive deepening of the access channel.
\end{abstract}

\section{Introduction}

Estuaries and coastal regions are reservoirs of fine sediments derived from continental basins. The Patos Lagoon, located in southern Brazil $\left(30^{\circ}\right.$ and $32^{\circ} \mathrm{S}$ latitude and $50^{\circ}$ and $52^{\circ} \mathrm{W}$ longitude) (Fig. 1), is classified as a coastal choked lagoon (Kjerfve, 1986), connected to the Atlantic Ocean by a narrow channel, which presents intermittent fine sediment (silt and clay) exportation towards the continental shelf controlled by the continental discharge and meteorological forcing (Calliari et al., 2009). The material exported by the Patos Lagoon reaches the coastal region through the coastal plume (Marques et al., 2010b) and, eventually, these sediments are deposited in the inner shelf and nearshore zone of Cassino Beach. This deposited material contributes to the formation of muddy banks observed in the region (Calliari et al., 2009), which are sporadically remobilized by specific waves, wind and current conditions towards the shore (Holland et al., 2009).

The exportation of fine sediment towards the coast is a natural process occurring in the region even before the construction of the breakwaters, when an ebb delta was observed at the mouth of the Patos Lagoon estuary. The construction of the breakwaters finished in 1907 and remained unchanged until recently (2010), when the Port of Rio Grande received investments from the Brazilian Government to expand its draft in a progressive way (Fig. 2), and to modify the configuration of the breakwaters. Once again, it is expected that this new anthropogenic modification changed the hydrodynamics, and consequently, the bottom and suspended fine sediment distribution in the region. The aim of this study is to evaluate the new patterns of sediment distribution inside the Patos Lagoon access channel and at the coastal region after the modernization work.for such a claim.

\section{Methodology}

The hydrodynamic model TELEMAC-3D (LNH-EDF) coupled with the morphodynamic model SediMorph (Federal Waterways Engineering and Research Institute and UniBw) were used to perform two 225 days (01/01/1998 to 


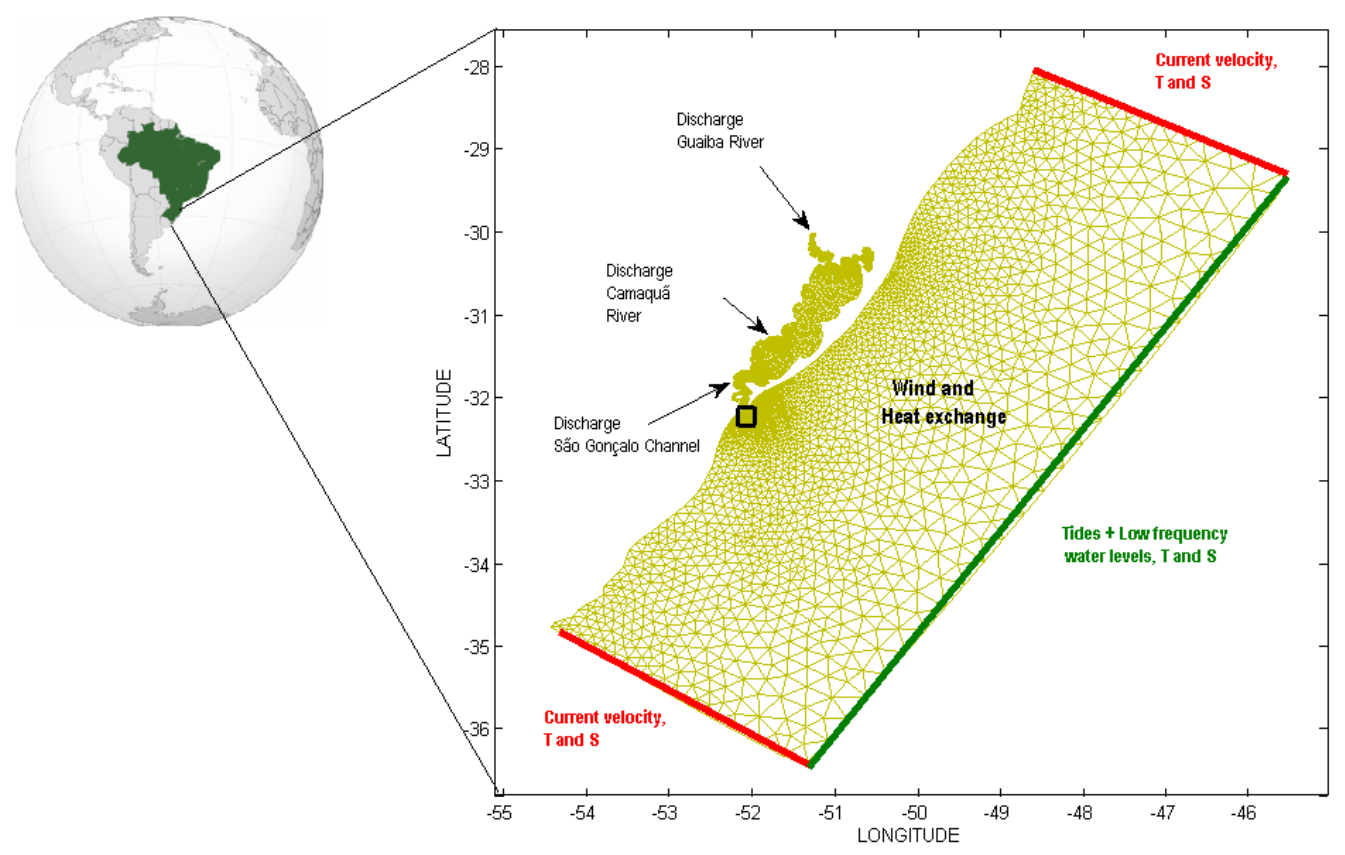

Figure 1. Location of the Patos Lagoon, combined with the model domain finite element mesh, highlighting the prescribed boundary conditions. The black square indicates the area presented in Fig. 2.

13/08/1998) long numerical simulations based on the Port of Rio Grande old (Fig. 2a and b) and new configurations (Fig. 2c and d). The domain was discretized through a finite element triangular mesh with 8974 nodes and 15 vertical sigma levels (Figs. 1 and 2).

TELEMAC-3D solves the Navier Stokes equations by considering local variations in the free surface of the fluid, neglecting the density variations in the mass conservation equation, and considering the hydrostatic pressure and Boussinesq approximations. Hervouet (2007) presents the model in details.

The SediMorph model, is a morphological and fractionated sediment transport model. It works coupled to the hydrodynamic model TELEMAC-3D (Marques et al., 2010b) and is calculated with the same time step, resulting in the bed load transport of sediments, erosion flux, and bed shear stress to update the evolution of the seabed. At the interface layer where the erosion and deposition processes occur, the model must calculate the bottom shear stress and consider the roughness of the bed and the intensity of the flow. The bed roughness summarizes the effects of the geometrical irregularities in the flow. This information is updated during the simulation according to the bed evolution transferred for TELEMAC-3D. The SediMorph formulation is described in detail by Malcherek et al. (2005), and calculates the bottom shear stress using a slightly modified Nikuradse formula, the transport of bottom sediments using the Hunziker formula, and an erosion flux model with quadratic approximation to

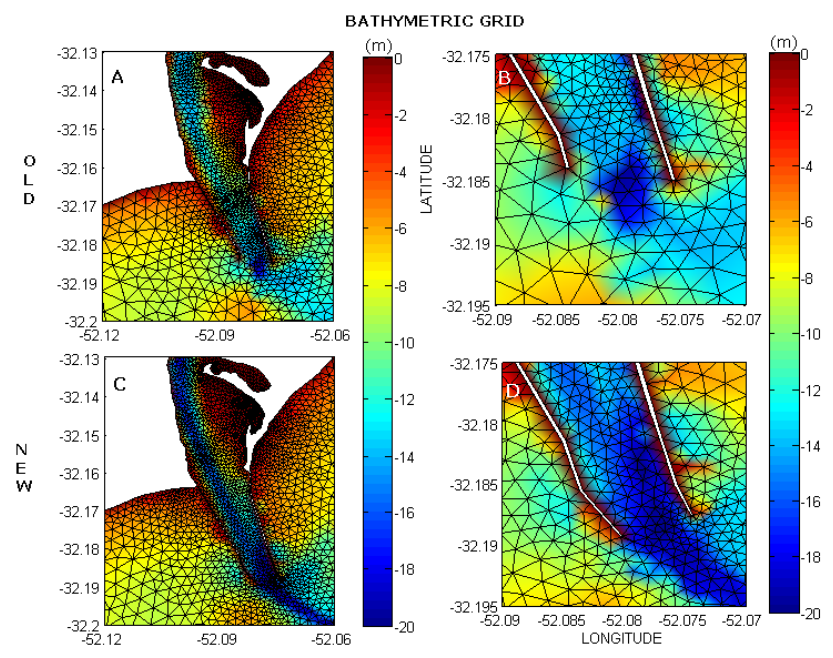

Figure 2. Zoom of the finite element mesh for the two simulated scenarios: (a) and (b) before, and (c) and (d) after the modernization work carried out at the Port of Rio Grande.

consider the effects of cohesion and the Van der Waals interaction between sediments settled over the bottom.

SediMorph uses a classification sediment file, which defines the different classes according to the diameter and density of each one. This information is used to construct a bidimensional non-structured bottom mesh with several vertical levels performing a tridimensional mesh of finite volumes. In this study, only one vertical level was used, due to the lack 
of information about the vertical distribution of bottom sediments in the area.

\subsection{Initial and boundary conditions}

Initial conditions of salinity and temperature fields were established for the TELEMAC-3D model based on the OCCAM Project (Ocean Circulation and Climate Advanced Modeling Project; http://www.soc.soton.ac.uk). An initial water level of $0.4 \mathrm{~m}$, which is approximately the mean value of the tides in the studied region, and a null velocity field was also prescribed in the entire domain.

On the continental border (Fig. 2), river discharges were prescribed for the main tributaries in the studied area (Jacuí and Camaquã, Rivers), based on values from the National Water Agency's (www.ana.gov.br, ANA). On the ocean border (Fig. 2), amplitude and phase data for the five major tidal components (K1, M2, N2, O1 and S2), obtained in the Grenoble Model FES95.2 (Finite Element Solution - v.2004) were prescribed.

The surface boundary of the model (Fig. 2) was forced with space and time variable winds from Reanalysis (National Oceanic \& Atmospheric Administration - NOAA, www.cdc.noaa.gov/cdc/reanalysis), with spatial and temporal resolution of $2.5^{\circ}$ and $24 \mathrm{~h}$, respectively, which were interpolated for each nodal point of the mesh. The heat exchange between the free surface of the model and the atmosphere was included using daily air temperature data from Reanalysis interpolated for each node of the mesh.

The seasonal and annual variability was imposed on the numerical simulation by considering the remote wind effects represented by the water level low frequency variation imposed at the oceanic boundary (Fig. 2). The influence of the buoyancy-driven currents from the La Plata River was considered by establishing salinity time series at each nodal point at the boundaries (Fig. 2). The heat balance between different water masses was considered through the prescription of temperature time series. The monthly variability of the currents along the domain was represented by the prescribed current velocity time series implemented tridimensionally along the transversal boundaries of the model (Fig. 2). These data sets were obtained from the OCCAM Project and prescribed tridimensionally along the entire transversal and oceanic boundaries (Fig. 2).

The initial SediMorph condition was a null initial concentration of suspended solids in the entire domain. Constant values of suspended solids concentration were considered $\left(0.5 \mathrm{~kg} \mathrm{~m}^{-3}\right.$ for the discharge of the Guaíba River and $0.3 \mathrm{~kg} \mathrm{~m}^{-3}$ for the Camaquã River) (Niencheski and Windom, 1994) as boundary conditions. Initial conditions of bottom sediment distribution were prescribed for the use of the morphodynamic model. The classes of sediments prescribed are distributed as fine silt, fine sand and coarse sand in the lagoon and estuarine region of the Patos Lagoon. For the

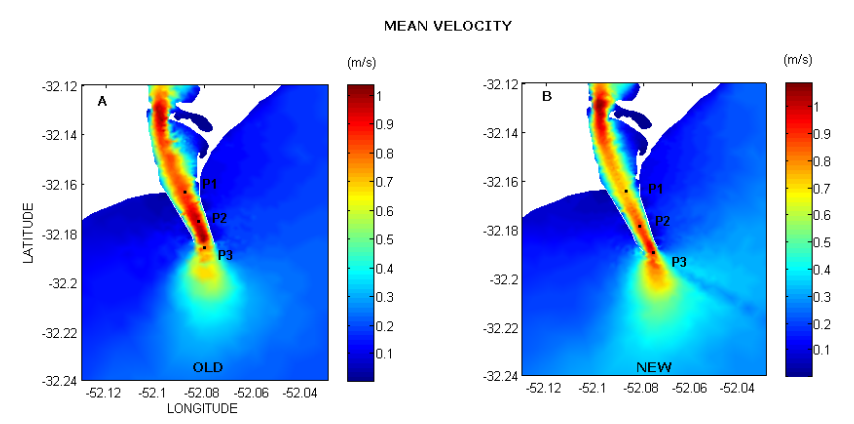

Figure 3. Mean ebb velocity fields calculated by TELEMAC-3D for the two simulated scenarios: (a) before, and (b) after the modernization work carried out at the Port of Rio Grande.

bottom of the coastal region the presence of fine sand was defined for the entire area.

The calibration and validation of the TELEMAC3D hydrodynamic module and the coupling between TELEMAC3D + SediMorph was presented by Marques et al. (2009, 2010a, b) using velocity data, salinity, water level and satellite images.

\section{Results}

\subsection{Estuarine and coastal hydrodynamics}

A preliminary analysis of the simulated period indicates that ebb conditions dominated $80 \%$ of the time. Based on that, hydrodynamic results were analyzed in terms of mean ebb conditions.

Figure 3 presents the mean velocity field calculated by TELEMAC-3D for the area close to the mouth of the Patos Lagoon estuary, where differences on the geometry of the simulated scenarios are more evident. Results indicate a clear reduction in the mean velocity along the main access channel after the Port of Rio Grande modernization work (Fig. 3b) in comparison with the previous configuration of the access channel (Fig. 3a). At the mouth of the estuary, however, the coastal plume jet increases (Fig. 3b).

These tendencies were analyzed in more detail throughout the water column at points P1, P2 and P3 (Fig. 4), corroborating the results and indicating a reduction of $13 \%$ in the mean velocity in points $\mathrm{P} 1$ and $\mathrm{P} 2$ and an increased of $16 \%$ in point P3. These results would be expected when considering that the channel cross section increased due to the deepening of the channel in the $\mathrm{P} 1$ and $\mathrm{P} 2$ region, and decreased at the mouth (P3) due to the convergence of the breakwaters.

Figure 5 presents the mean velocity vectors calculated by TELEMAC-3D for the whole period of the simulation and for both scenarios. A preliminary comparison between the results, considering lines $\mathrm{L} 1$ and $\mathrm{L} 2$ as a reference, indicate changes in the dynamics of the coastal currents. Apart from the intensification of the mean currents at the mouth and ev- 


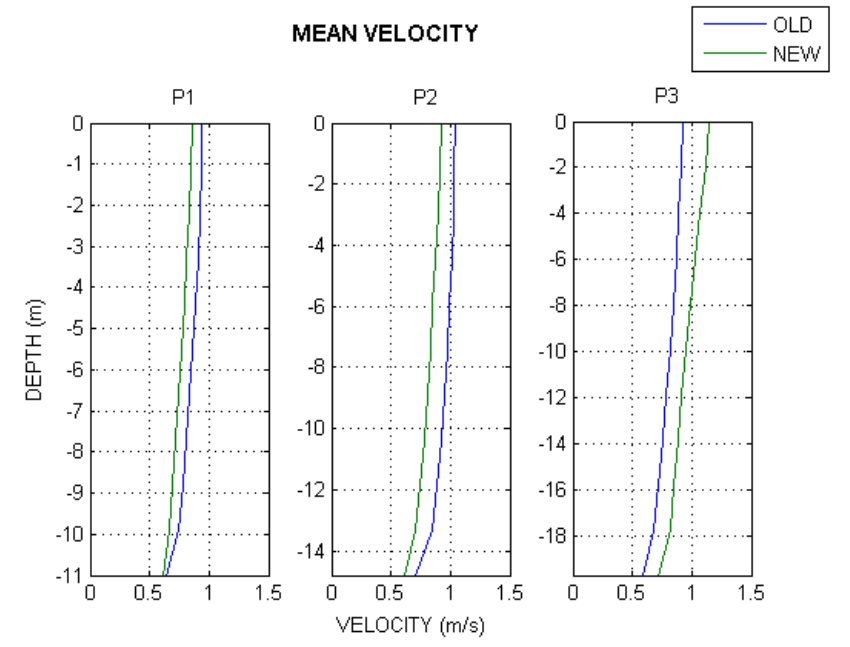

Figure 4. Mean velocity profiles calculated by TELEMAC-3D for points $\mathrm{P} 1, \mathrm{P} 2$, and $\mathrm{P} 3$ in the two simulated scenarios.

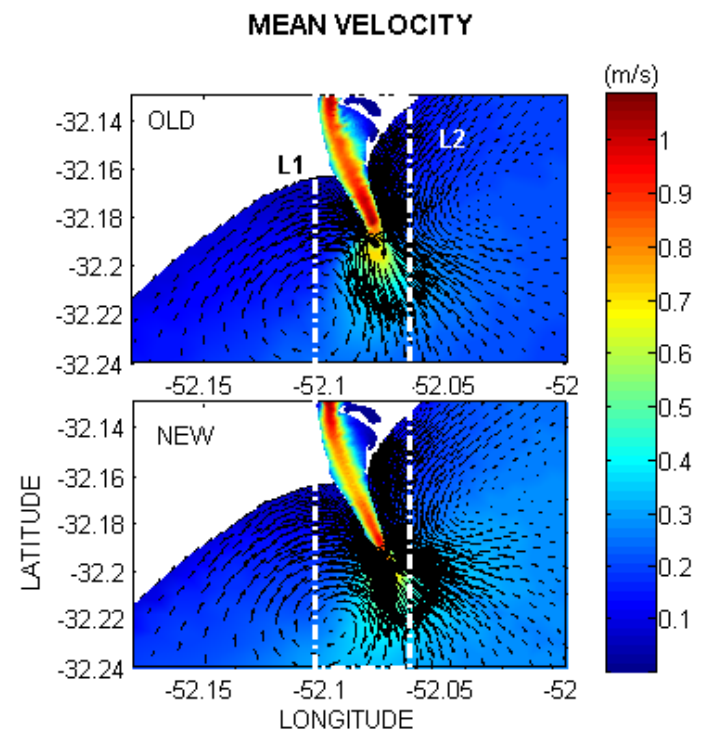

Figure 5. Mean velocity vectors calculated by TELEMAC-3D for the whole period of simulation for both scenarios.

ident change in the coastal plume direction, the recirculation zones occurring at the north and south of the breakwaters were also intensified and displaced in relation to the old scenario.

It is expected that these hydrodynamic changes observed in the estuarine and coastal areas after the Port of Rio Grande modernization work will have direct effects on the fine sediment dynamics in these areas.

\subsection{Estuarine and coastal sediment deposition fluxes}

Figure 6 presents the mean deposition flux of fine silt calculated by the coupling between TELEMAC-3D and Sedi-

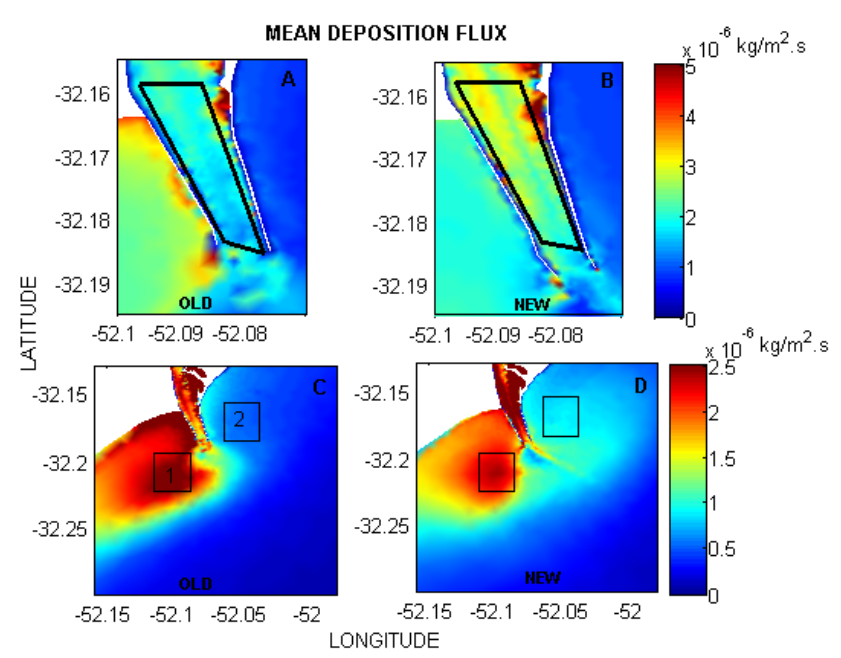

Figure 6. Mean deposition flux of fine sediment calculated by the coupling between TELEMAC-3D and SediMorph, highlighting the estuarine and coastal areas considered in the calculations.

Morph, highlighting results for the estuarine and coastal areas. When integrating these results for the area of the rectangle located inside the access channel (Fig. 6a and b), results indicate a mean deposition rate of $3.61 \mathrm{~kg} \mathrm{~s}^{-1}$ for the old scenario, rising to $5.20 \mathrm{~kg} \mathrm{~s}^{-1}$ after the modernization work, suggesting an increase of up to $44 \%$ in the fine silt deposition along the access channel. These results are in agreement with the decrease in the mean velocity observed for this area (Fig. 3), but in disagreement with the main purpose of the modernization work, which expected to promote the autodredging of the system.

A similar analysis was carried out for AREA 1 and AREA 2 (Fig. 6c and d) located outside the breakwaters. Results indicate a mean deposition rate of $14.20 \mathrm{~kg} \mathrm{~s}^{-1}$ at the north of the breakwaters (AREA $2=15.91 \mathrm{~km}^{2}$ ), and $31.48 \mathrm{~kg} \mathrm{~s}^{-1}$ at the south (AREA $1=15.91 \mathrm{~km}^{2}$ ), suggesting an increase of $74 \%$ and a decrease of $8 \%$ in the fine sediment deposition in these areas, respectively. These results corroborate the observed changes in the hydrodynamics of these areas.

\section{Conclusions}

Results from this preliminary study indicate that the modernization work carried out at the Port of Rio Grande changed the hydrodynamics and the fine sediment dynamics in the estuarine and coastal regions of the Patos Lagoon. The extension of these changes needs further investigation, especially regarding changes in the temporal scale of the system response to the main forcings (remote wind and freshwater discharge). Furthermore, changes in the dynamics of the Patos Lagoon coastal plume are evident and also need further study, as it has direct implications on the formation of muddy banks at the coast. 
Edited by: F. Metivier

The Supplement related to this article is available online at doi:10.5194/-15-123-2015-supplement.

\section{References}

Calliari, L. J., Winterwerp, J. C., Fernandes, E. H., Cuchiara, D., Vinzon, S. B., Sperle, M., and Holland, K. T.: Fine grain sediment transport and deposition in the Patos Lagoon-Cassino beach sedimentary system, Cont. Shelf Res., 29, 515-529, 2009.

Hervouet, J.-M.: Hydrodynamics of free surface flows: modeling with the finite element method, John Wiley \& Sons, Ltd, The Atrium, Southern Gate, Chichester, 2007.

Holland, T., Vinzon, S. B., and Calliari, L. J.: A field study of coastal dynamics on a muddy coast offshore of Cassino Beach, Brazil, Cont. Shelf Res., 29, 503-514, 2009.
Kjerfve, B.: Comparative oceanography of coastal lagoons, edited by: Wolfe, D. A., in: Estuarine Variability, Academic Press, New York, 63-81, 1986.

Malcherek, A., F. Piechotta, and D. Knoch.: Mathematical module SediMorph-Validation document, version 1.1, Technical Report, Federal Waterways Engineering and Research Institute, Germany, 2005

Marques, W. C., Monteiro, I. O., and Fernandes, E. H.: Numerical modeling os Patos Lagoon plume, Brazil, Cont. Shelf Res., 29, 556-571, 2009.

Marques, W. C., Fernandes, E. H. L., Moraes, B. C., Möller, O. O., and Malcherek, A.: Dynamics of the Patos Lagoon coastal plume and its contribution to the deposition pattern of the southern Brazilian inner shelf, J. Geophys. Res., 115, C10045, doi:10.1029/2009JC005653, 2010a.

Marques, W. C., Monteiro, I. O., Fernandes, E. H., and Möller, O. O.: Straining and advection contributions to the mixing process of the Patos Lagoon costal plume, Brazil, J. Geofhys. Res., 115, C06019, doi:10.1029/2009JC005653, 2010b.

Niencheski, L. F. and Windom, H. L.: Nutrient fluxand budget in Patos Lagoon Estuary, Sci. Total Environ., 149, 53-60, 1994. 